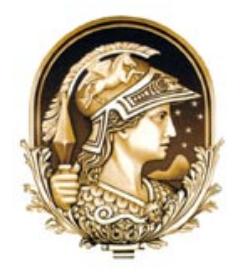

Anuário do Instituto de Geociências - UFRJ

\title{
Evidências de Anomalias Ósseas em Stahleckeria potens Huene, 1935 (Therapsida, Anomodontia)
}

Evidences of bone anomalies in Stahleckeria potens Huene, 1935

(Therapsida, Anomodontia)

\author{
Cibele Schwanke ${ }^{1} \&$ Diogo Jorge de Melo $^{2}$ \\ ${ }^{1}$ Pesquisador IVP/FAPERJ; Procientista UERJ. Universidade do Estado do Rio de Janeiro, Instituto de Biologia Roberto Alcântara \\ Gomes. Rua São Francisco Xavier, 524, Pavilhão Haroldo Lisboa da Cunha, sala 506. CEP 20550-900. Rio de Janeiro, Brasil. \\ E-mail:schwanke@uerj.br \\ 2 Programa de Pós-Graduação em Geologia. Universidade Federal do Rio de Janeiro. Bolsista CAPES. \\ E-mail: diogojmelo@gmail.com \\ Recebido em: 30/03/2007 Aprovado em: 27/07/2007
}

Os dicinodontes representam um grupo de tetrápodes herbívoros amplamente registrado em rochas sedimentares do Permiano Superior e Triássico. Uma das espécies mais instigantes é Stahleckeria potens Huene 1935, uma forma de porte avantajado cujos fósseis, até o momento, foram registrados unicamente em sedimentos mesotriássicos da Formação Santa Maria (Bacia do Paraná, Brasil). Nos últimos anos, novos materiais atribuídos a $S$. potens têm sido identificados aumentando consideravelmente o conhecimento da morfologia da espécie. A análise comparativa de dois fêmures esquerdos depositados no Museu de Ciências da Terra (DNPM/RJ) evidenciam anormalidades ósseas significativas (DGM 155-R e DGM- 399-R), aqui apresentadas preliminarmente e sugestivamente associadas a patologias. O espécime DGM 399$\mathrm{R}$ caracteriza-se por apresentar uma acentuada depressão na região da epífise distal. Esta depressão localiza-se na face anterior do osso, lateralmente posicionada e possui um formato grosseiramente circular, criando uma espécie de platô nesta região, acompanhada por um leve deslocamento ósseo. Em oposição, na face posterior do osso, há um pequeno sulco de formato claramente semicircular, onde são visualizadas cerca de sete pequenas perfurações rasas, que demonstram certa regularidade, porém sem formato definido. Tais feições sugerem que as alterações ósseas presentes no espécime possam estar associadas a lesões ou traumas decorrentes de diversos fatores. Embora não observado claramente, há evidências de cicatrização local, hipótese que vem sendo analisada mais detalhadamente a partir da utilização de técnicas de maior precisão e resolução, como tomografia computadorizada e microscopia eletrônica de varredura. A ocorrência de uma extensa região marcada pela presença de estrutura óssea irregular, diferente do padrão normal linear, pode ser interpretada como decorrente de remodelação do periósteo, resultante de um processo inflamatório, provavelmente associado às depressões descritas, o que reforça a idéia de que tais anomalias ósseas tenham sido ocasionadas durante a vida do animal. O segundo espécime (DGM 155-R) apresenta uma extensa área claramente desgastada, formando uma depressão que percorre parte da face posterior da epífise proximal e se prolonga até o início da diáfise, aparentemente resultante da fossildiagênese. Uma análise mais detalhada desta depressão nos permite observar além das perdas tafonômicas, estruturas que sugerem a existência de um remodelamento ósseo, que pode ter atingindo grande parte da região cortical do osso. Em áreas associadas a esta região, encontram-se indícios de remodelamento do periósteo, caracterizado por estrutura óssea irregular, sugerindo a existência de algum processo traumático ou infeccioso. Dessa forma, é possível inferir que esta alteração esteja associada a um processo de inflamação óssea gerado por infecções, distensões musculares ou fraturas em outros membros ou ossos da mesma pata, que possam ter afetado a postura e a locomoção do animal. Assim, considera-se que o desgaste pós-morte local tenha sido facilitado pela presença de uma estrutura mais fragilizada do osso remodelado nesta região. 